The beach dissolves as the heart image swells and spirals into the centre of the screen, dissolving into an image of her dentist, looking as if she is standing in her dental office ...

\section{Twenty years in the future}

T

he young woman sits in her living room, enjoying breakfast. The wall opposite her is a huge screen, showing a beautiful beach, early morning sunlight glinting on the waves, their soft lapping creating a soothing background. To the bottom left of the screen are two smaller active windows, one informing her she has electronic mail, the other constantly displaying news items that she has muted for the moment.

Now, suddenly, a warm-red heart begins to pulse in the lower right of the screen. This is the image she has chosen for any health warnings due. Alerted, she picks up a small hand control version of the wallscreen and touches the tiny heart image to activate it. The beach dissolves as the heart image swells and spirals into the centre of the screen, dissolving into an image of her dentist, standing in her dental office, yet looking as if she is in an adjoining room. The image is so clear that the young woman almost forgets her dentist is not in the room with her.

'Your dental checkup is due,' the electronic dentist says. 'Would now be convenient? It should only take ten minutes.'

'Yes' the woman replies and the dentist image reminds her to fit her personal examination appliance (PEA). The woman slips into the bathroom, takes a small headgear appliance from its box in the bathroom cabinet, sets it in place over her head and around her mouth, and returns to her living room.

By now the image has changed and the whole screen (from ceiling to floor) resembles a chart containing a number of questions about her medical and oral health and her lifestyle. She takes a moment to read through them then says 'Yes to four and six, the rest are no' and her dentist image reappears. She asks the woman to close her teeth together, move her jaw from side to side and forward and back and open her mouth wide. As she does so tiny electronic impulses within the PEA record her occlusal contacts and send the digital information back to the dental surgery via optic cables within the appliance attached to her main cable input.

Next the young woman fits clear plastic overlays to both her upper and lower dental arches, that fit snugly over both teeth and gums. For thirty seconds relays whirr and click, infra-red and ultraviolet lights glow, plaque and saliva are collected and sampled, her teeth are digitally examined inside and out. 'You need a clean-up' the dentist informs her, and a fine spray is ejected from her appliance to froth, sherbet-like, around her teeth for ten seconds and then be rinsed away so she can swallow the harmless residue safely.

'Your upper left premolar had early signs of decay' her dentist said, 'so I programmed preventive measures to halt it. However, I would suggest we consider a physical check in the next six months, and a digital check after three months.' The young woman replies 'Okay' as a message appeared on the wall asking her to verify the suggestion was acceptable.

'Would you like to choose any additional options today?' the image of her dentist asks. A series of smaller windows appear on the screen covering topics like 'aesthetics', 'prevention', 'long term' and 'recent advances'. She chooses the last, and the dentist disappears to be replaced by a short video describing some of the latest dental advances available.

Finally the dentist reappears to ask if she is interested in anything in particular. She shakes her head, and her dentist wishes her good morning before fading away to be replaced by the beach scene again.

Sounds improbable? I suspect the most improbable thing about it is my estimate of how soon before it arrives. After all, virtually all the technology I have described is with us now. 